\title{
La inclusión y el afecto un dilema sociocultural
}

\author{
Inclusion and affection a socio-cultural dilemma
}

\section{Resumen}

\author{
Reyes Roman Dorinda Mireya \\ Universidad Técnica de Machala \\ dmreyes@utmachala.edu.ec \\ Machala - Ecuador

\section{Flores Macías Adriana María} \\ Universidad Técnica de Machala \\ aflores4@utmachala.edu.ec \\ Machala - Ecuador
}

\section{Peña Aguilar Rolando Michael}

\author{
Universidad Técnica de Machala \\ rpeña4@utmachala.edu.ec \\ Machala - Ecuador
}

La inclusión de niños y niñas es un proyecto de investigación-acción, cuyo objetivo es aplicar el afecto como eje transversal. Representa la compleja realidad de niños y niñas de una escuela pública de Ecuador. La mayor parte de los infantes tienen necesidad de atención y cuidado. Directivos y profesores se sienten impotentes frente a la situación sociocultural que viven a diario su alumnado. Esta investigación contribuye al desarrollo social a través de prácticas socioeducativas y comunitarias. El análisis crítico permitió transformar las observaciones en oportunidades para que niños y niñas experimenten interacciones que mejoren su entorno de injusticia e inequidad.

Palabras clave: inclusión, afecto, investigación-acción, pobreza, políticas públicas.

\begin{abstract}
The inclusion of children is an action - research project, whose objective is to apply affection as a transversal axis. It represents the complex reality of children in a public school in Ecuador. Most infants need care and attention. The school administrators and teachers feel powerless in the face of the sociocultural situation that their students live on a daily basis. This research contributes to social development through socio-educational and community practices.
\end{abstract}

Keywords: inclusion, early education, action research, poverty, public policies 


\section{Introducción}

Plantear la investigación acción educativa en niños y niñas de educación inicial contribuyó a crear vínculos afectivos entre pares en un contexto conflictivo, reduciendo los niveles de agresividad que existía en estos grupos de edad. Los retos eran modificar las formas de cuidado y atención de los infantes a través del análisis de las prácticas diarias de trabajo, convirtiendo el aula de clases en espacios de reflexión sobre sus propias experiencias y características de la población atendida en la unidad educativa, provocadas por las situaciones de violencia intrafamiliar.

Como lo menciona Freire (1980) "El hombre llega a ser sujeto sobre su situación, sobre su ambiente concreto. Mientras más reflexiona sobre su realidad, sobre su situación concreta, más "emergente", plenamente consciente, comprometido, dispuesto a intervenir respecto a la realidad para cambiarla" (p.48). Encuentros que servían para promover el afecto como medio de socialización y buen trato de pequeños y pequeñas en su entorno. Todo ello, contribuiría a la inclusión de forma natural y espontánea, instaurando un ambiente afectivo, de buen trato, de paz y armonía, donde la inclusión no solo consiste en integrar con estrategias apropiadas; implica también valorar su diversidad sociocultural.

El Ministerio de Educación debería promover programas educativos conforme al contexto social que los envuelve, porque la cultura de cada comunidad se definen por sus habitantes, lo cual, daría respuesta a la necesidad educativa que tiene cada localidad, considerando el currículo como una respuesta a las problemáticas sociales, con el objetivo de prevenir la exclusión social que aparece de forma reiterada en diversos contextos sociales como consecuencias de las características socioculturales, de género, de clase, étnicas, lingüísticas, entre otras.

\section{Detalle del escenario de investigación}

Este es un estudio de caso vertebrado sobre una investigación acción en una escuela situada en el Cantón ecuatoriano de Machala, aquejada de importantes y graves problemas sociales de exclusión. Concretamente se desarrolló en la etapa inicial (22 niños y niñas de 3-5 años), con la intención de analizar, discutir y transformar prácticas de los implicados, docentes, niños, niñas y familias en una dirección emancipadora, buscando construir relaciones inclusivas donde la conciencia y el respeto en relación a los derechos de la niñez resultaría esencial.

Este trabajo responde a una deuda social con la madre de la autora que laboró en la institución, escenario central de la investigación, por 34 años, y que, al llegar al hogar, constantemente narraba un sin fin de historias, de miserias e injusticias que a diario vivían el alumnado y sus familias. Tales relatos al ser escuchados por la investigadora irían sembrando en su corazón una marea de inquietudes que le llevarían a desear fervientemente hacer algún día algo por aquellos 
niños y niñas que no pidieron venir al mundo y que eran a menudo maltratados física, psíquica y socialmente.

\section{Materiales y Métodos}

Al tener la investigación un carácter cualitativo inductivo-descriptivo, donde los participantes de la investigación son sujetos de pleno derecho y con voz propia, estudiados desde diferentes perspectivas, teniendo en cuenta sus percepciones y/o consideraciones acerca de las situaciones y problemas investigados. A través de la investigación basada en el estudio de caso colectivo mismo que está relacionado con lo mencionado por Stake (1994) citado por Paz (2003) quien enuncia “...Estudio colectivo de casos. El interés se centra en la indagación de un fenómeno, población o condición general.

El estudio no se focaliza en un caso concreto, sino en un determinado número de casos..." (174), permitió comprobar que el aplicar el afecto como eje transversal y sinónimo de buen trato a un grupo de niños y niñas promovió un enfoque inclusivo en las prácticas de las profesoras. Con el objetivo de resolver el problema, se llegan a consensuar procedimientos sistemáticos que permitieron generar procesos de reflexión-acción, donde se determinaron las pautas para cambiar el entorno educativo, cuya finalidad era reducir los niveles de violencia y agresividad en la escuela. La información recopilada a través de la observación, entrevistas, documentos de campo, fotografías, evidencias documentales y análisis bibliográfico sirvió para cualificar los datos y triangular los mismos.

\section{Investigación acción de los implicados}

\section{Directivo, profesores e infantes}

La violencia intrafamiliar, los hogares disfuncionales, el narcotráfico y la delincuencia de la zona influían poderosamente en la vida de los infantes, medio social que no promovía el ingreso de autoridades locales para bajar los niveles de riesgo, provocó cierto conformismo, por el temor del profesorado a represalias. Las situaciones de peligro constante que rodeaban la escuela, la falta de compromiso social afectaba la búsqueda del bien común educativo, tornándolo como una utopía.

De esta problemática social eran conscientes él directivo, profesoras y profesores que laboraban en este sector con más de 30 años. La investigadora tenía el apoyo de todos los docentes, sin embargo, no pensaban que se podría lograr un cambio social en la escuela, por los problemas sociales que la rodeaban. En las actividades diarias de educación inicial, no se percibía afecto en las interrelaciones, resaltaba un ambiente educativo sombrío, sin alegría, motivación, compañerismo. 
Cada infante vivía su mundo, algunos en el refrigerio comían, otros no. La maestra no tenía iniciativa para que compartan, escuchaba repetidas veces "no te manda nada tú mamá", en cambio a otros infantes les compraban en el bar algo que cueste $\$ 0,50$ que era el presupuesto. Un entorno evasivo, hostil, lejos de la responsabilidad y compromiso social. La investigación acción aspira alcanzar grandes cambios en la atención, cuidado, modificar este enfoque excluyente por uno inclusivo a través de buenas prácticas del buen vivir y el afecto como eje transversal.

\section{Las familias}

El entorno investigado con los problemas sociales descritos y una cultura machista reflejada en el control sobre la esposa, impidiendo su desarrollo integral, terminaba convertida en una fuente de modelos de comportamientos en las familias, arquetipos peligrosamente, son socializados a niños y niñas, generando una carencia de ambientes cálidos y armónicos, dominando diversas formas de opresión y exclusión, cuya influencia sobre los comportamientos infantiles en los ambientes escolares ha de ser analizada, interpretada y explicada.

La intervención con las familias se canalizo en talleres, en donde directivo y profesoras presentaron a la investigadora, quienes al recordar a su madre que trabajó en la institución, se mostraron con buena actitud y predisposición para contribuir a mejorar el ambiente de aprendizaje y buen trato de los infantes. Es así, como se obtiene apoyo total de las familias para el proceso que se emprendió de investigación.

\section{Estrategias en acción y acuerdos}

En junio del año 2015, la propuesta socializada en el consejo ejecutivo, fue una oportunidad para sensibilizarlos sobre la problemática socioeducativa, donde se logran acuerdos con la investigadora y apoyos mutuos para emprender cambios que posibiliten mejorar el ambiente institucional. Se debe agregar, la ligereza y paciencia que debe tener el investigador al momento de solicitar autorización para realizar la investigación, que es parte esencial para vincularse al campo de investigativo (Taylor y Bogdan, 2009).

Siendo de esta manera, uno de los objetivos de la investigadora en los primeros meses abordar e involucrarse con los docentes, familias, niños y niñas, con el fin de que las visitas de observación contribuyan a conocer la problemática psicosocial y emocional, lo cual concuerda con Sánchez, (2005) "la investigación proceso de aceptación mutuo, en el que estaban implicados diferentes grupos sociales de la escuela" (p.57).

Al final, este proceso de investigación tiene algunos retos importantes que se centran dentro del término inclusión, donde se pretende a través de los métodos utilizados, generar procesos de diálogo con los docentes, para promover ambientes cálidos que fortalezcan las relaciones humanas con enfoque de derechos, corresponsabilidad, valores, que fomenten y contribuyan al buen vivir institucional. 
El mantener una comunicación rapport con los informantes generó satisfacción, empatía, confianza y conllevó a un clima agradable de interacciones en los procesos de indagación y recolección de información de datos provenientes de entrevistas y observaciones (Taylor y Bogdan, 1984). Acercamientos que mejoraron la comunicación entre docentes e investigadora, lo cual fue analizado y reflexionado en conjunto, buscando vías de solución a las formas de comportamiento, no solo de los infantes, sino también de las familias, que son la razón de ser de la labor docente. La negociación no tuvo complicaciones.

\section{Triangulación}

La investigadora se adaptó a los tiempos y espacios de las docentes, lo cual, facilitó el proceso de investigación, ajustándose el proyecto a las necesidades e intereses de los participantes. Por lo tanto, las maestras serán quienes a través de las múltiples razones por las que se tiene que intervenir en la escuela, influirán para tener efectos positivos y sean sus prácticas las que determinen los cambios que ameritan.

Frente a los resultados, la investigación social es parte esencial, porque permite que los datos obtenidos irlos sistematizando y analizando en el transcurso de las notas de campo, lo cual es una característica específica de la investigación cualitativa, que es la diferencia que le da valor y realce, porque los cambios son tangibles, objetivos, se perciben en la reflexión-acción (Gibbs, 2012). Según Taylor y Bogdan (2009) afirman "Las observaciones son útiles sólo a media en que pueden ser recordados y registrados" (p.53). Dicho de otra manera, los datos recogidos con las diferentes técnicas etnográficas aplicadas permitieron tener información confiable, que admitió triangular los datos y dar a conocer los resultados.

\section{Las espirales de reflexión acción}

Los períodos importantes en el contexto investigativo durante el estudio preexistieron: El recibimiento de los infantes y su familia, las actividades lúdicas, las discusiones, los acuerdos, los rincones de aprendizaje, el desarrollo de planificaciones curriculares, el refrigerio, el recreo, la despedida y retiro a los hogares.

Las espirales de reflexión giran principalmente en torno a lo siguiente:

- Entender el contexto sociocultural

- La inclusión sin ningún tipo de discriminación.

- Incluir con afecto a niños, niñas y familias.

- Construcción de valores

- Ambientes de aprendizaje

- Trabajo cooperativo a través del juego

\section{Primera espiral}


Las maestras estaban conscientes que el problema actitudinal que tenían los infantes, se debía al contexto social violento que los envuelve. Las transformaciones más importantes de las maestras, fue que se comprometieron en cambiar sus prácticas de enseñanza involucrando el afecto en todo momento, para que este pase por los sentidos, reflejado en el sentirse bien con los otros, ser aceptado y vinculado sin ningún tipo de discriminación, asimilando, el mismo trato con las familias.

El cambio de actitud de las maestras con niños y niñas generando el buen trato con equidad e igualdad en función de las necesidades individuales, sin discriminación sea por: etnia, cultura, capacidad cognitiva, buen comportamiento; provocó bajar los niveles de agresividad y equilibrarse emocionalmente consigo mismo y con los demás.

\section{Segunda espiral}

Las maestras comprenden que las palabras dulces como mi papito, mi niña, mi amor, provocan reacciones positivas en los pequeños y pequeñas, relacionado que es el trato que quisieran tener y no lo reciben en su hogar, por lo que consideran relevante mantener una reflexión crítica sobre sus acciones para analizar los valores axiológicos que se deberían promover, para mejorar el entorno de aprendizaje.

En función de esta reflexión crítica se promueven campañas internas y externas cada mes, tendría el nombre de un valor, por ejemplo "enero mes de la amistad". Esta práctica transforma el entono escolar de los infantes, reduciendo los niveles de agresividad, haciéndolos conscientes de la importancia del buen trato a través de afecto y promoviendo los valores, como la mejor forma de incluir y generar empatía.

\section{Tercera espiral}

El director inmerso dentro del proceso de concienciación amplia a los infantes de educación el área de atención para que familias y maestras diseñen rincones de aprendizaje, originando el desarrollo del juego-trabajo como parte del proceso de enseñanza aprendizaje, convirtiéndose en los espacios ideales donde maestros y discentes se interrelacionen de manera libre y espontánea como: escuchar, contar y dramatizar cuentos, narraciones e historias, juego libre, juego simbólico y juegos dirigidos, aplacando la violencia en el convivir diario, lo que permitió desarrollar el área psico-socio-afectivo, promoviendo estabilidad emocional, empatía y tolerancia entre los participantes. Espacios que permitirían a niños y niñas sentir las mismas oportunidades, enfocándose en tratar temas que construyan resiliencia en los participantes.

\section{Cuarta espiral}

Las actividades de expresión corporal, artísticas, lúdicas, a través de la conformación de grupos intercalados en las tareas intraclase de las planificaciones curriculares, fue sembrando en niños y niñas principalmente la solidaridad, colaboración y coordinación entre compañeros, logrando 130 
generar un grupo comprometido y afectuoso. En este sentido, observar cómo se transformaban los gritos por saludos gentiles con abrazos y besos, los golpes por palmadas, la falta de comunicación por diálogos, fueron las actitudes que aportaron a consolidar un entorno de buenas prácticas y relaciones sociales amigables e incluyentes entre discentes y maestras.

La participación a través del trabajo cooperativo de los infantes se denota en el salón de clases, en el patio. En el caso de un niño a quien llamaremos Juan, quien tenía problemas de conducta a veces incontrolables, se logró incluirlo a través del afecto en todos los grupos de trabajo. El reto fue ofrecer un ambiente que permita el cambio de actitudes y construir un ambiente de respeto, trabajo mutuo, colaborativo, siendo posible con el compromiso social de las maestras.

\section{Discusión}

A pesar de vivir profundos problemas sociales a diario, la investigación acción contribuiría a cambiar las expectativas del profesorado en relación a esta infancia desfavorecida, siendo percibida, finalmente, como capaz y llena de posibilidades (Sánchez Blanco, 2018). Las categorías representan nudos críticos establecidos a partir del análisis y discusión de los resultados del problema objeto de estudio. El análisis de los datos recogidos en esta investigación acción revelarían, finalmente, que la inclusión solo es posible en un marco de, equidad, solidaridad y justicia social, con la cooperación comprometida de maestros y maestras, donde las familias tendrían que ocupar un papel fundamental.

El trabajo de investigación hizo posible definir un conjunto de estrategias que convirtieron el afecto en eje transversal del trabajo docente con la infancia y las familias, desarrollando formas de pensar y de hacer, conectadas con la liberación de conciencias y la búsqueda de la justicia; además, permitió analizar políticas que han de seguir laborando en pro de la lucha contra la exclusión y configurando contextos socioeducativos en los cuales se desarrollen y aprendan niños y niñas.

Al respecto, Cussiánovich (2015) señala que la inteligencia, las emociones y relaciones interpersonales son bases del desarrollo, afirmando que en materia educativa y pedagógica sino se establece un vínculo constructivo y positivo, no hay proceso educativo, refiriéndose a la pedagogía de la ternura como la mejor alternativa para tocar el mundo interior. Dimensiones necesarias en la lucha constante por la dignidad, libertad y bienestar, contribuyendo a conformar el mundo de la subjetividad, denominada la segunda piel.

\section{Inclusión, pobreza y discriminación}

A pesar de las condiciones desfavorables del contexto de la escuela, se saltaron barreras para incluir en la diversidad, se trasgredieron ideologías, actitudes, estructuras, condiciones y prácticas opresivas (Darder, 2017). En este sentido, Paulo Freire (1970), desde sus primeros escritos hizo aportaciones claves, esenciales y trascendentales sobre la opresión, la desigualdad, 
la injusticia y la inequidad, que continúan siendo un referente esencial para luchar contra las situaciones de exclusión y la búsqueda de la justicia y la emancipación de conciencias.

El pensamiento de este autor se convertiría en esencial para orientar el trabajo de investigación acción con las docentes en torno a la lucha contra la exclusión, llegando a entender que basta con que un sujeto logre salir de la opresión, para que este pueda incidir en toda una posible generación venidera, pues se estarán transformando sus relaciones y expectativas (Lucas, 2017). Una de las principales barreras que impiden la inclusión, es la pobreza.

Se han ido direccionando políticas que han reducido la pobreza, entendida por Escribano y Martínez (2013), "como la carencia de recursos para satisfacer necesidades consideradas básicas que influyen en la calidad de vida de las personas" (p.80). En este desafío no hay que olvidar que en Ecuador la pobreza se encuentra ubicada en contextos históricamente y geográficamente determinados y que existe su contrapuesto que es la riqueza (Cimadore y Donato 2013).

El contexto evidenciado en esta investigación, la lucha contra la exclusión social, donde las razones de índole económica ocupaban un papel fundamental, requiere poner el acento en niños y niñas menores de cinco años y sus familias, pues sabemos que atendiendo a las familias atenderemos a los infantes; y brindando atención a la infancia atenderemos a las familias. Sin embargo, no hay que perder de vista, que no faltan las ocasiones en las cuales la atención a los progenitores no es garantía de una atención a la infancia; y es por ello, que se ha de constatar que la ayuda a las familias llegue verdaderamente a los pequeños y pequeñas, necesidades de protección y afecto (Fondo de las Naciones Unidadas para la Infancia (UNICEF), 2014).

La escuela tendría que tener siempre presente, como afirman Papalia et al. (2010), que la pobreza, sobre todo si es duradera, es perjudicial para el bienestar físico, cognoscitivo y psicosocial de los niños y su familia. Los niños en condiciones de pobreza tienen más probabilidades de sufrir problemas emocionales o conductuales (p.12). Las familias participantes en este estudio son personas de etnia mestiza y afroecuatoriana, sacudidas por problemas derivados de la pobreza y el analfabetismo. Ecuador, a través de los Ministerios del Estado, ha generado estrategias para disminuir los efectos de la pobreza y la discriminación y la exclusión étnica y cultural. (Plan Nacional de Desarrollo (PND), 2017-2021).

A pesar de la existencia de tales iniciativas las familias de la escuela apenas si salían beneficiadas de ellas. Vivían importantes situaciones de estrés, cansancio y malestar por los problemas económicos que vivían y que a veces derivaban en situaciones de maltrato hacia el profesorado de sus hijos e hijas. Estas circunstancias ahondaban en los procesos de exclusión, pues las maestras no querían a las familias en el centro ante el temor de ser agredidas por ella.

Por tanto, el tomar distancia respondía a una necesidad de protección. El haber desarrollado la investigación en un sector donde el más fuerte gana y manda, la exclusión social era parte de la vida misma de las familias y en particular de las mujeres. Los testimonios de algunas de ellas 
nos dan cuenta de la posición de propiedad del varón que ocupaban y que algunas asumían con gran orgullo, mostrando públicamente las huellas de los hombres en su cuerpo. Para ellas representaban una muestra del poder de sus dueños y estaban de acuerdo.

En los hogares más pobres había mujeres a las cuales las parejas varones les tenían prohibido trabajar para que no abandonaran la casa, temiendo que encontraran una nueva pareja. Debían encargarse de la casa, la ropa, los hijos, entre otros quehaceres domésticos. El hambre que pasaban por la falta de recursos no era causa suficiente para trabajar y tenían prohibido quejarse. Este fue uno de los mayores problemas que enfrentaban las familias dando lugar a riñas y no pocas peleas. En este ambiente, los niños y niñas aprendían a ser niños y a ser niñas, asumiendo roles en sus juegos que denotaban bien a menudo el machismo y la violencia que vivían a diario. Con este panorama, inicialmente el profesorado mostraba un profundo pesimismo en sus expectativas en relación a las familias, considerando que hablar con ellas, pedirles participación, era como "arar en el mar".

Pensaban que a ellas no les gustaba participar, ni cuidar del desarrollo de sus hijos e hijas en la escuela. Frente a este ambiente, los docentes comienzan a trabajar en algunas estrategias de participación para las familias como talleres de buen trato, derechos, buen vivir; iniciándose tímidamente las actividades, consiguiendo aumentar su confianza y reducir los niveles de ansiedad de algunas familias que comenzaron retraídamente a participar, en su mayoría mujeres. Estas actividades dieron lugar a diálogos que fueron generando empatía en la comunidad educativa, que serviría para que todos se sintieran incluidos.

Por un lado, se iba produciendo un cambio en la percepción y consideración hacia la escuela de sus hijos e hijas; por otro, las maestras perdían miedos y se sentían valiosas en su trabajo al ser escuchadas y consideradas y, finalmente, los niños y niñas eran capaces de disfrutar en la escena escolar y mostrarlo, porque los adultos eran, por fin, ellos mismos capaces de hacerlo. Sin embargo, ciertas formas de comportamiento de las familias, asumidas como parte de un ethos sociocultural construido y con el cual se identificaban, limitaban el lograr un mayor grado de sensibilización.

A través del buen trato que las maestras brindaban y las mismas actividades que se proponían y donde se involucraban, las familias descubrirían que disfrutaban jugando con sus hijos e hijas. Se generaban y fortalecían, así, vínculos afectivos entre adultos, niños y niñas, lográndose producir brechas en la desigualdad e inequidad. Las familias se dieron cuenta de los activos, decididos y valiosos que eran sus hijos e hijas; e incluso ellas mismas, capaces de aportar a la comunidad respeto y conocimiento, asistencia y solidaridad, trabajo y aprendizaje, recursos y amor (Lynch et al., 2014).

En este contexto, el profesorado también modificó sus prácticas educativas. A lo largo de primeros meses se observaron los prejuicios y estereotipos presentes en las prácticas de los maestros y maestras, vertebrados sobre las características del alumnado y sus familias, que eran alimentados tanto por los comportamientos disruptivos de niños y niñas, como por las actitudes 
desafiantes de las familias en la escuela frente a sus normas y también, porque en más de una ocasión llegaron a agredir a docentes.

Finalmente, los docentes entendieron que la agresividad de los niños y niñas no iba contra ellas, sino que era una manifestación del desamor y la falta de cuidados que vivían a diario. La situación hizo necesaria una formación para construir estrategias de protección hacia la infancia y de un buen trato sobre ella; así como, para abrir caminos de entendimiento mutuo entre las familias y el profesorado.

Escribano y Martínez (2013), afirman que “el concepto de inclusión va más allá del simple concepto de integración. La inclusión, exige una nueva forma de pensar acerca de las diferencias y la diversidad como algo valioso en sí mismo que pide un tratamiento educativo y social adecuado" (p. 17). La integración no es inclusión. Un alumno para sentirse incluido dentro de un grupo ha de llegar a participar plenamente, siendo considerado como miembro de pleno derecho en el seno del mismo.

El profesorado ha de entender la diversidad como una fuente de riqueza en el aula, de manera que las diferencias vienen a dignificar a las personas, nunca a empequeñecerlas (Felber, 2012). El entorno violento vivido por los infantes deja heridas que serán superadas, sólo si acontecen procesos de resiliencia, en relación a los cuales la escuela tiene un papel esencial, al incorporarlos como parte de su cultura infantil; una cultura que en ningún caso será única, sino que habrá tantas como infancias. Hoyuelos y Riera (2015), afirman que "la cultura de la infancia, supone reconocer que los niños y niñas tienen su forma ética, estética y poética, de ver el mundo, de construir sus hipótesis, teorías y metáforas que dan sentido a su vivir y existir" (p.118).

Finalmente, es necesario aclarar que, evidentemente, el consumo y el tráfico con estupefacientes en las familias era uno de los temas que sobresalía en la comunidad. Este tema no fue nunca objetivo de esta investigación, aunque le afectara directamente, pues el problema requería de la intervención especializada de diferentes sectores del Estado en corresponsabilidad con las familias y la sociedad civil. Sin embargo, se considera que este estudio, de alguna manera, contribuiría a que algunas familias abandonaran o al menos se replantaran su papel no sólo como vendedoras, también como consumidoras, al tomar conciencia de las repercusiones que los estupefacientes estaba teniendo en sus hijos e hijas.

Los procesos de concienciación, como diría Freire (1970), resultan esenciales para que emerjan procesos emancipadores capaces de liberar a las personas de su condición de oprimidos. Esa toma de conciencia representa, así, el primer paso para desear cambiar las situaciones de injusticia, generadoras de violencia y exclusión y proceder para contribuir a su transformación.

\section{Inclusión y desarrollo de afectos}


El ser humano, desde que está en el vientre de su madre recibe información sobre el mundo exterior, sobre el contexto cultural en el cual pertenece su familia. Estas primeras informaciones contribuirán decisivamente a construirse como persona y miembro de un grupo. Es en el núcleo familiar donde obtendrá los primeros encuentros con los afectos y desafectos, aprenderá a reconocerse a sí mismo y a conocer a los otros. En este se enfrentará también a todo tipo de situaciones que le afectarán emocionalmente, aprendiendo o no a sobreponerse al desamor y en general, a las situaciones más o menos traumáticas que las provocan a través de procesos de resistencia y resiliencia.

La inclusión requiere del análisis de las situaciones escolares que puede recrear la inclusión versus la exclusión (Sánchez Blanco, 1997); también son creadas y alimentadas desde fuera de ella (orden social, familiar, del entorno y de los barrios, o quizás desórdenes). Todo ello requerirá de un análisis crítico para caminar hacia la inclusión (Escudero et al., 2009). Un medio desfavorable y/o favorable en el que crecen, se desarrollan y aprenden niños y niñas les devolverá siempre una imagen de sí mismos como capaces o incapaces que influirá de forma decisiva en su crecimiento como seres humanos, para bien y para mal; el desafío estará en aprender a enfrentar las adversidades, logrando poner en marcha estrategias de resistencia que transforme la dificultad en posibilidad y la destrucción en construcción. Los docentes críticos, comprometidos, tienen un papel muy importante en los procesos para revertir los efectos del desamor y la exclusión.

En este contexto, las discusiones mantenidas provocaron en los docentes un autorreflexión sobre su propia cultura, su condición social y sus tradiciones, interiorizando la necesidad de un respeto profundo a la interculturalidad y, por tanto, desarrollando la capacidad de colocarse en el lugar del otro, entendiendo sus sentimientos, sus deseos, sus expectativas que les llevarían a valorar sus logros (Nussbaum, 2012). Por consiguiente, el instaurar el afecto como medio de inclusión fue una de las mejores medidas para reducir las afectaciones sociales con las que llegaban niños y niñas, para estabilizarlos emocionalmente como medida inclusiva. Permitiría reducir la conducta agresiva, que era una consecuencia de la exclusión social.

Los resultados que se iban obteniendo en función de las observaciones impulsaron en las maestras reflexiones éticas que las llevaron a entender la importancia de los afectos que prodigaban a los pequeños y pequeñas en las clases. El afecto favorecía en los infantes, desarrollaran compañerismo, respeto confianza y relaciones inclusivas, disminuyendo las tensiones que se sentían en el clima escolar. Según Pérez, et al. (2016), afirman "lo que hace la escuela es reorientar los valores que de hecho se forman en la vida social. La escuela reeduca; la sociedad, educa. La escuela reorienta los valores; la sociedad, los forma" (p.9).

El trabajo en la investigación acción hizo notar la importancia de convencer utilizando los afectos, muy alejada de las ideas de obligar a aprender con la disciplina. Entendieron entonces el papel que juegan las emociones y los afectos en los aprendizajes y comenzaron a cambiar sus estrategias de enseñanza. De esta forma, por ejemplo, el niño y/o niña que no quería 
participar, finalmente se sentaba un rato y miraba jugar a sus compañeros/as para luego acabar involucrándose con el grupo, sin sentirse presionado.

Muchas veces su inhibición era producto de un malestar emocional que finalmente lograba manejar al desahogarse con su maestra y/o en el juego con sus iguales. Muy a menudo sus pesares guardaban estrecha relación con maltratos sufridos en las familias. Al respecto, Rivero et al. (2013), afirman que aquellos niños y niñas que en su contexto no les permite ser afectivos o expresar afecto, la maestra es capaz de incluirlos utilizando estrategias educativas destinadas al manejo de sus emociones.

De las observaciones realizadas en las jornadas de las maestras se evidenció que un clima de afecto era esencial para conocer situaciones que inquietaban a niños y niñas, logrando llevarlos a un estado más equilibrado, tranquilo, pacífico, feliz. Las maestras afirmaban: "siempre hemos escuchado hablar del afecto en todas las actividades; sin embargo, aplicarlo en función del contexto ha sido diferente". Felber (2012) afirma que "los niños aprenden a reconocer los sentimientos, a tomarlos en consideración, a no avergonzarse y hablar sobre ellos” (p.154).

Conforme pasó el tiempo, el afecto prodigado por las docentes hizo posible que niños y niñas comenzaran a confiar perdiendo la vergüenza y el miedo a la participación, comenzando a involucrarse en las actividades lúdicas. En este sentido, Freire (1980) refería que el amor y la confianza desarrollada a través del diálogo como práctica epistemológica, era la mejor forma de tomar consciencia sobre el mundo y transformar la vida de las personas.

Asimismo, las maestras dentro del marco de inclusión aplicaron actividades grupales, que requirieron de la cooperación de todos y todas para organizarse, desarrollando en niños y niñas valores y afectos que primaron en las relaciones interpersonales e intrapersonales, que contribuyeron a restablecer espacios de convivencia pacífica. Por ejemplo: cuando la docente generaba una actividad educativa referente al cuerpo humano, ella promovía el aprendizaje a través de sensaciones placenteras, de manera que comenzaban a valorar su propio cuerpo a través del juego.

La narración de cuentos donde la dramatización formaba parte, estaba destinada a originar en la infancia emociones diversas y estados de ánimo que guardaran relación con las experiencias diarias que vivían en sus familias, de manera que sirvieran para su elaboración afectiva. Por tanto, lograr experiencias y vivencias colectivas resultaría muy importante para construir un sentimiento de grupo que serviría para llenar de afectos positivos, algunas veces prácticamente inexistente en la familia. La familia escolar se convertía, así, en un punto de apoyo esencial para el desarrollo socio-afectivo de niños y niñas. De esta forma los vínculos afectivos comenzaron a aparecer, no solo entre ellos y los adultos, también con sus iguales.

Las muestras de afecto entre los participantes comenzaron a evidenciarse en pequeñas acciones: las miradas, el saludo, los juegos, entre otros, que acreditaba los cambios en el convivir diario de niños y niñas; sin embargo, después de fines de semana, al regresar a la escuela, se notaba 
cargas de agresividad, tensión, entre otros aspectos que era reflejado en los juegos bruscos que mantenían entre ellos y ellas, como una forma de reproducir las experiencias vividas en el hogar. Así, aparecían juegos de matar, de guerra, de policías, de superhéroes, entre otros.

Todo ello tenía que ser tenido en cuenta en las prácticas docentes por su incidencia en los procesos inclusivos que se querían instaurar (Ritscher, 2017; Sánchez Blanco, 2006-2013). Las docentes trataban de mitigar estas situaciones con mucha paciencia a través del afecto y los diálogos interactivos que mejoraban las relaciones interpersonales e intrapersonales y también con juegos físicos que aliviaban la agresividad y el estrés como carreras, saltos y todo tipo de juegos de motricidad gruesa. Estos representaron un poderoso antídoto contra la agresividad, cuando se practican sin alentar la competición entre iguales y sí, en cambio, promoviendo las ganas de superarse uno mismo. Desde esta perspectiva, las maestras implementaban constantemente actividades con alto valor lúdico.

En este sentido, Nussbaum (2010) señala que, si preparamos a los niños y niñas como seres humanos conscientes de sí mismos y del mundo que les rodea, motivando su autonomía física y emocional estos crecerán con pensamientos que le permitan superar tendencias que afecten su integridad. Mantener un clima de aprendizaje saludable condujo a impulsar una pedagogía centrada en la infancia, consciente de sus derechos; entendiendo sus necesidades y particularidades y resaltando el papel que juega el afecto en su desarrollo, así como las relaciones afectivas que mantienen entre sí los adultos que conviven con ellos.

Al respecto, Lynch et al. (2014) afirma "las relaciones primarias de asistencia no son sostenibles en el tiempo sin el trabajo del amor" (p.59). Una finalidad esencial de la inclusión sustentada sobre los afectos fue crear un ambiente capaz de impulsar el amor por uno mismo y por los demás, ofreciendo contextos donde las acciones son valoradas y la participación impulsada.

\section{Inclusión y necesidad de cuidados}

Las maestras olvidaban a menudo la necesidad de contacto físico y de los cuidados corporales, con carácter afectivo, tan necesario en el desarrollo de niños y niñas en sus múltiples facetas, piedra angular de la lucha contra la exclusión en los escenarios escolares. Los contactos físicos y cuidados corporales organizados y casuales con los pequeños y pequeñas han de estar presididos por emociones capaces de repercutir de forma positiva en la vida infantil. A raíz de la investigación acción, tales interacciones se convertirían en objeto de preocupación, haciendo que el profesorado tomara conciencia de que el amor y la asistencia constituyen una necesidad humana básica (Lynch et al. 2014).

Niños y niñas en su inocencia, buscaban roces de amor, cuidado, relaciones interpersonales a través de sus contactos corporales, donde tenía cabida la intervención de las profesoras, que de alguna manera llenaba los vacíos que tenían las criaturas. A través de los cuidados físicos practicados con respeto y compromiso con los derechos de la infancia, los críos comenzarían a protagonizar menos episodios agresivos. En este sentido, Sánchez Blanco (2006) se refiere a la 
importancia de los cuidados en la infancia para aminorar las agresiones físicas entre los escolares de la etapa infantil.

Los infantes iban deshaciéndose de actitudes a la defensiva, viniendo a ser remplazadas por relaciones de confianza, que se traducían corporalmente en que sus cuerpos estaban más relajados. El profesorado acabaría por interiorizar tales cuidados como promotores de una convivencia plena y respeto a la diversidad en la clase áulica de educación inicial. La vida en las aulas de clase estaba llena de situaciones imprevistas, muchas relacionadas con las demandas de cuidados, entre los que se encuentra todo lo relativo al cuidado corporal; si los maestros y maestras las toman en cuenta, las reconocen y las observan se convertirán en oportunidades de aprendizaje de todo tipo para ellos mismos y ellas mismas.

Los cuidados y la inclusión van de la mano, de manera que sin cuidados no hay inclusión y sin inclusión no hay cuidados. Pero además estos cuidados brindaban la oportunidad a los docentes de destapar maltratos físicos que podrían estar sufriendo los niños y niñas. En las actividades escolares que se evidencian como rutinas, los cuidados están encubiertos, inmersos en cada minuto de la jornada diaria, no existiendo inicialmente una reflexión al respecto de las docentes, de manera que en estos cuidados existían desigualdades que afectaban a la inclusión.

La investigadora era consciente de este hecho; si persistían, crearían barreras emocionales que impedirían la participación espontánea de los niños y niñas. Los procesos de reflexión-acción de esta investigación permitieron superar los obstáculos enunciados. En este sentido, Sánchez Blanco (2013) se refiere a "la necesidad de analizar en la escuela los significados que pequeños y pequeñas van construyendo en torno a los contactos corporales, y las repercusiones que tales percepciones tienen en la vida social del aula" (p.61). En cualquier caso, no hemos de perder de vista que los cuidados estarían siempre conectados al respeto a los derechos de la infancia.

En este sentido, la escuela al tener como finalidad enseñar a través de procesos de reflexión del pensamiento, que estimule sus acciones en la jornada, pero de manera consiente, para proyectar en los estudiantes efectos positivos como el amor, la credibilidad, la generosidad y principalmente, la responsabilidad de sus actos, pretendía poner en alerta los cuidados de su cuerpo y el de sus compañeros, protegiéndolo de situaciones que le podrían afectar su integridad, a pesar de que, como afirma González et al. (2007), "algunos seres logran superar condiciones severamente adversas y que, inclusive, logran transformarlas en una ventaja o un estímulo para su desarrollo biopsicosocial” (p.38).

La investigación acción favorecería que el profesorado tomara conciencia de los derechos de niños y niñas y de la necesidad de ser respetados, pues eludirlos significaba la exclusión. En cuanto a las familias, se procedió en la misma dirección, pero para ellos lo más importante fue darse cuenta de las consecuencias que podrían producir la falta de cuidados en sus hijos e hijas. De esta forma, el trabajo con ellas estuvo encaminado a impulsar hábitos saludables implícitos en los cuidados; como, por ejemplo, una adecuada nutrición y descanso nocturno, asuntos que se extendieron a la práctica docente en la escuela. 
Al respecto, Dubois (2011), señala que "cuanto más conscientes seamos de nuestras propias vulnerabilidades, seremos menos propensos a distanciarnos del cuidado y tendremos mayores posibilidades de percibirlo como una actividad que es fundamental, y no marginal, para nuestras vidas" (p.13). Al mejorar los cuidados se contribuiría a garantizar el desarrollo integral de niños y niñas, derribando barreras que representaban fuentes de exclusiones, permitía concientizar sobre la inclusión en todos los ámbitos: educación, salud, nutrición, participación, afecto. Se convertirían en palabras generadoras que dieron paso a otras bien importantes como: justicia, inclusión, responsabilidad, compromiso. La esperanza acudía con los cuidados y los cuidados acudían con una vida más esperanzada, producto de la lucha colectiva y no derivada de una espera perpetua de salvación (Freire, 1970). 


\section{Conclusiones}

La desidia inicial de las familias en las relaciones con sus hijos e hijas y la aceptación de su situación como algo absolutamente natural que extinguía cualquier deseo y/ o esperanza de cambio estaba en sintonía con la propia desesperación sentida por los docentes y que comenzaba a sentir la investigadora. Sin embargo, sería el recuerdo del trabajo de su madre Rosa, el detonante de ese primer rayo de esperanza en los participantes para acometer tan duro propósito consistente en devolverle la dignidad a una población que hacía años se había convencido de que les había tocado por destino no merecer nada de aquello que en justicia les correspondía. Este recuerdo de que hubo tiempos mejores en la escuela, cuando la madre de la investigadora trabajaba en ella, fue, sin lugar a dudas, el detonante de comenzar a pensar que un futuro para esos niños y niñas era posible.

Desear asumir el papel de protector/a de sus hijos e hijas sería una ardua tarea que haría su aparición en el transcurso del desarrollo de los proyectos al descubrir cuan capaces y valiosos eran sus niños y niñas, despertándose afectos y emociones positivas que habían sido arrinconadas en un entorno tan hostil, como era aquel en el que vivían. Tomaron también conciencia de lo importantes que eran en la casa, alejándose de la idea de los hijos e hijas como estorbo, cuando colaboraban ayudando, en la medida de sus posibilidades.

A medida que fueron avanzando los proyectos, las mujeres fueron cambiando su aspecto físico, que se fue dibujando como más cuidado y por supuesto más digno. Sin embargo, el problema de los estupefacientes representó siempre en la investigación un hueso muy duro de roer que hasta la fecha sigue sin resolverse, pues son muchos los habitantes del vecindario que han hecho de las drogas su medio de subsistencia. En este sentido, sí que se puede decir, que la investigación al menos abrió un camino para que las autoridades tomaran cartas en el asunto, en un territorio que inicialmente en este tema había sido abandonado a su suerte.

La investigadora misma, cuando inició esta investigación, viviría en propias carnes situaciones de impotencia en las tareas que demandaba su trabajo investigativo. Trabajando con una población tan extremadamente pobre y en un barrio tan terriblemente conflictivo como el que se ha retratado. 


\section{Referencias}

Cimadamore, D. y Donato, M. (2013). Introducción. En Gentili, P (Ed.). La Construcción de la pobreza en América Latina y El Caribe. Perspectivas, alternativas y críticas. 11-22. Buenos Aires, Argentina: CLACSO_CROP.

Cussiánovich, A. (2015). La Pedagogía de la Ternura-Una lucha por la dignidad y la vida desde la acción educativa, Editorial Universidad Don Bosco, 16, 63-76.

Darder, A (2017). Freire y educación. San Sebastián de los Reyes, Madrid, España: Morata.

Dubois, A. (2011). La cooperación y el desarrollo local humano: Retos desde la equidad de género y la participación social. En Larrañaga, M. y Jubeto, M.(Coord.). Prólogo (617). Madrid, España, Editores: UPV/EHU y Hegoa.

Elliot, J. (1993). El cambio educativo desde la investigación-acción. Madrid, España: Morata.

Elliott, J. (1999). La Investigación-acción en educación. Madrid, España: Morata.

Escribano, A. y Martínez, A. (2013). Inclusión educativa y profesorado inclusivo. Madrid, España: NARCEA, S.A.

Escudero, J., González, B. y Martínez, B. (2009). El fracaso escolar como exclusión educativa: comprensión, políticas y prácticas. Revista iberoamericana de educación. 50, 41-64.

Felber, C. (2012). La economía del bien común. Madrid, España: Deusto.

Freire, P. (1970). Pedagogía del Oprimido. México: Fondo de Cultura Económica.

Freire, P. (1980). El mensaje de Paulo Freire: Teoría y Práctica de la Liberación. Madrid, España: INODEP.

Gibbs, G. (2012). El análisis de datos cualitativos en Investigación Cualitativa. Madrid, España: Morata.

González, A., López, N. y Valdez , J. (2007). Resiliencia en Niños: Psicología Iberoamericana, Red de Revistas Científicas de América Latina, 15 (2), 38-50. México. Recuperado de: http://www.redalyc.org/pdf/1339/133915933006.pdf.

González, N. (2018). Autoestima, Optimismo y Resiliencia en Niños en Situación de Pobreza. Revista Internacional de Psicología, 16(01).1-22.

Hoyuelos, A. y Riera M. (2015). Complejidad y relaciones en educación infantil. Barcelona, España: Octaedro.

Lucas, M. (2017). La orientación familiar y las carencias afectivas en el desarrollo del escolar ecuatoriano. Revista de educación 13(1), 66-75. Recuperado de: http://scielo.sld.cu/pdf/trf/v13n1/trf07117.pdf.

Lynch, K., Baker, J. y Lyons, M. (2014). Igualdad afectiva: Amor, cuidados e injusticia. Madrid, España: Morata.

Nussbaum, M. (2010). Sin fines de Lucro: Por qué la democracia necesita de las humanidades. Barcelona, España: Katz.

Nussbaum, M. (2012). Crear Capacidades. Barcelona, España: Herder S.A.

Oalleyne, G. (1996). La violencia en las Américas. Washington DC: Organización Panamericana de la Salud, 1, 15-20.

Papalia, D., Wendkos, S. y Duskin, R. (2010). Desarrollo humano. México: S.A. de C.V. 
Pérez, E., Álvarez, J.; Aguilar, J., Fernández J. y Salguero D. (2013). El diálogo como instrumento para la resolución de conflictos en escolares de educación secundaria. Red de Revistas Científicas de América Latina, el Caribe, España y Portugal, 2 (1), 184-194.

Pérez, J. (2016). Reciprocidad Socio-pedagógica del Educando. Revista educación, 838 - 850.

Pérez, G. (1994): Investigación cualitativa. Retos e interrogantes I y II. Madrid, España: La Muralla.

Reitscher, P. (2017). La escuela slow: pedagogía de lo cotidiano. Barcelona, España. Ediciones Octaedro.

Rivero, I., Gómez, M. y Abrego, R. (2013). Tecnologías educativas y estrategias didácticas: criterios de selección. Revista Educación y Tecnología, 3, 190-206.

Sánchez, C. (1997). La Cooperación en educación infantil: Dilemas de una investigaciónacción. Coruña, España. Publicación Universidad da Coruña.

Sánchez, C. (2013). Infancias nómadas: educando en el derecho a la movilidad. A Coruña, España. Miño y Dávila.

Sánchez, C. (2013). Pobreza, alimentación y juego en la educación infantil. Revista Iberoamericana de educación, 62, 261-277. Recuperado de: https://dialnet.unirioja.es/servlet/articulo?codigo $=4773499$.

Sánchez, C. (2015). Learning about democracy at school: an action research project in early childhood education, Educational Action Research, DOI: 1-15.

Sánchez, C. (2018). Fuego Meteoritos y elefantes. Cruzando fronteras en desarrollo infantil. A Coruña, España. Miño y Dávila.

SENPLADES, N. (2017). Plan Nacional de desarrollo 2017-2021: Toda una vida. Recuperado de: http://www.planificacion.gob.ec/wp-content/uploads/downloads/2017/10/PNBV26-OCT-FINAL_0K.compressed1.pdf.

Segato, L. (2016). La guerra contra las mujeres. Buenos Aires, Argentina: Traficantes de sueños.

Stake, R. (2007). Investigación con estudio de casos. Madrid, España: Morata.

Taylor, S. y Bogdan, R. (1987). Introducción a los métodos cualitativos de investigación. Barcelona, España: Paidós

UNICEF. (2015). Nacionalidades y pueblos indígenas, y políticas interculturales en Ecuador. Una mirada desde la Educación. Unicef. Recuperado de https://www.unicef.org/ecuador/nacionalidades_y_pueblos_indigenas_web_Parte1.pdf Upload/20116619450revista_integracion5.pdf Una versión abreviada de este artículo se encuentra en: http://cultural.argenpress.info/2010/03/sumaq-kawsay-ninchik-onuestrovivir.html

Zuñiga, K. y Villavicencio, C. (2015). Afectividad infantil. Trabajo de titulación. Repositorio de la Universidad Técnica de Machala. repositorio.utmachala.edu.ec/handle/48000/4117. 